\title{
Fast and reliable calibration of solid substrate fermentation kinetic models using advanced non-linear programming techniques
}

\author{
M. Macarena Araya \\ Departamento de Ingeniería Química y de Bioprocesos \\ Escuela de Ingeniería \\ Pontificia Universidad Católica de Chile \\ Casilla 306, Santiago 22, Chile \\ Juan J. Arrieta \\ Department of Chemical Engineering \\ Carnegie Mellon University \\ Doherty Hall, 5000 Forbes Avenue \\ Pittsburgh, Pennsylvania 15213, USA \\ J. Ricardo Pérez-Correa* \\ Departamento de Ingeniería Química y de Bioprocesos \\ Escuela de Ingeniería \\ Pontificia Universidad Católica de Chile \\ Casilla 306, Santiago 22, Chile \\ Tel: 5623544258 \\ Fax: 562-354-5803 \\ E-mail: perez@ing.puc.cl

\section{Lorenz T. Biegler} \\ Department of Chemical Engineering \\ Carnegie Mellon University \\ Doherty Hall, 5000 Forbes Avenue \\ Pittsburgh, Pennsylvania 15213, USA \\ Fax: 14122687139 \\ E-mail: 1b01@andrew.cmu.edu

\section{Héctor Jorquera} \\ Departamento de Ingeniería Química y de Bioprocesos \\ Escuela de Ingeniería \\ Pontificia Universidad Católica de Chile \\ Casilla 306, Santiago 22, Chile \\ Fax: 562-354-5803 \\ E-mail: jorquera@ing.puc.cl \\ Website: http://www.ing.puc.cl
}

Financial support: Projects FONDECYT 1030325 and 7040084.

Keywords: dynamic models, Gibberella fujikuroi, Gibberellic acid, nonlinear models, parameter estimation, secondary metabolites, solid substrate cultivation.

Abbreviations: NLP: non-linear program

SeqSO: sequential solution/optimization

SimSO: simultaneous solution/optimization

SSF: Solid substrate fermentation

Calibration of mechanistic kinetic models describing microorganism growth and secondary metabolite production on solid substrates is difficult due to model complexity given the sheer number of parameters needing to be estimated and violation of standard conditions of numerical regularity. We show how advanced non-linear programming techniques can be applied to achieve fast and reliable calibration of a complex kinetic model describing growth of Gibberella fujikuroi and production of gibberellic acid on an inert solid support in glass columns. Experimental culture data was obtained under different temperature and

\footnotetext{
*Corresponding author
} 
water activity conditions. Model differential equations were discretized using orthogonal collocations on finite elements while model calibration was formulated as a simultaneous solution/optimization problem. A special purpose optimization code (IPOPT) was used to solve the resulting large-scale non-linear program. Convergence proved much faster and a better fitting model was achieved in comparison with the standard sequential solution/optimization approach. Furthermore, statistical analysis showed that most parameter estimates were reliable and accurate.

Solid substrate fermentation (SSF) can be defined as the cultivation of microorganisms on solid substrates devoid of or deficient in free water (Pandey, 2003). SSF has several advantages (Hölker and Lenz, 2005) over more conventional submerged fermentation, and many promising lab-scale SSF processes are periodically reported in the literature (John et al. 2006; Krasniewski et al. 2006; Lechner and Papinutti, 2006; Sabu et al. 2006). Unfortunately, very few of these processes enter commercial production (Hölker and Lenz, 2005) due to the magnitude of the technical difficulties in operating and optimizing large scale SSF bioreactors. Since modern process control and optimization engineering techniques are model based, mathematical modelling should significantly improve the chances of successfully transforming an SSF process from laboratory to commercial production.

Nevertheless, a number of factors make modelling SSF processes particularly trying: the absence of reliable on-line measurements of relevant cultivation variables (like biomass and nutrient concentration) and the system's inherent complexity, considering that microorganism interaction with the environment and its growth and production kinetics are still not well understood on a micro scale (Mitchell et al. 2004). In addition, the more useful mechanistic dynamic models proposed are highly complex and have many parameters that need to be estimated from extensive good quality experimental data. Acquiring such data is costly and time consuming and yet, even when this data is available, attaining reliable parameter estimates is far from trivial (Gelmi et al. 2002).

Therefore, in most current SSF lab-scale studies that include modelling, only simple black box or empirical kinetics models are used (Machado et al. 2004; Corona et al. 2005; Jian et al. 2005). However, these models can only reproduce process behaviour encountered in controlled conditions that are never found in large scale SSF bioreactors and, as such, more often than not commercial production yields are disappointingly low compared to labscale performance.

Parameters in dynamic fermentation models are commonly estimated using the sequential solution/optimization (SeqSO) procedure (Rivera et al. 2006). Though simple, this procedure may be severely limited when fitting complex models with many parameters or constraints that violate standard numerical regularity conditions, as is the case of more mechanistic SSF kinetic models. A high degree of heuristics is therefore required to overcome the method's slow convergence and unreliable estimation (Gelmi et al. 2002). Alternatively, the simultaneous solution/optimization (SimSO) approach (Biegler et al. 2002) is fast, robust and reliable, and have shown its suitability for fitting a variety of complex dynamic models.

In this work a SimSO procedure is developed to estimate model parameters in an SSF kinetic model and the results obtained are compared, in terms of fit quality and numerical performance, with those obtained with the commonly used SeqSO approach. The SimSO procedure developed was coded in AMPL and the resulting non-linear program (NLP) was solved using IPOPT (Biegler et al. 2002), a robust interior point NLP solver specially designed for large scale optimization problems. First, the model is described in brief and calibration details are provided. Then, results are shown and discussed, and finally the main conclusions of this work are presented.

\section{METHODS}

\section{Kinetic model}

We have used a slightly modified version of the lumped parameter model proposed in (Gelmi et al. 2002) to describe cultivation in glass columns of Gibberella fujikuroi grown on an inert support (Amberlite IRA-900), urea and starch. The main assumptions of the model are:

-Oxygen mass transfer resistance is negligible.

- Negligible temperature and concentration gradients within the solid substrate.

-Nitrogen is the only limiting substrate.

-Temperature and water activity remain constant throughout the cultivation.

Next, we present a brief description of the model.

The total amount of measurable dry biomass $\left(X_{t o t}\right)$ considers active and inactive fungi and is expressed on a dry total mass basis $\left(k g_{d \cdot b .}\right)$,

$$
\frac{d X_{t o t}}{d t}=\mu \cdot X \quad\left[k g_{X} / h \cdot k g_{d . b .}\right]
$$

Assuming a first order death rate, the active biomass $(X)$ is described by,

$$
\frac{d X}{d t}=\mu \cdot X-K_{D} \cdot X \quad\left[k g_{X} / h \cdot k g_{d . b .}\right]
$$

Here, $\mu$ and $K_{D}$ represent the specific growth rate and the specific death rate, respectively. 
The model assumes that urea, $U$, is degraded to assimilable nitrogen, $N_{I}$, following zero order kinetics and that Gibberella fujikuroi uses this nutrient for biomass growth,

$$
\frac{d U}{d t}=\left\{\begin{array}{c}
-k ; \quad \text { if } U>0 \\
0 ; \quad \text { if } U=0
\end{array} \quad\left[\mathrm{~kg}_{N} / \mathrm{h} \cdot \mathrm{kg} g_{d . b .}\right]\right.
$$

As this equation does not satisfy standard numerical regularity conditions we replaced equation (3) with the smooth approximation,

$$
\frac{d U(t)}{d t}=-\frac{k}{2}\left(1+\frac{(U o-k \cdot t)}{\left[(U o-k \cdot t)^{2}+\varepsilon\right]^{0 S}}\right)_{[4]}
$$

which is also used in the nitrogen balance below (5); $\varepsilon$ is a small number. The concentration of assimilable nitrogen is given by,

$\frac{d N_{I}}{d t}=0.47 \cdot \frac{k}{2}\left(1+\frac{(U o-k \cdot t)}{\left[(U o-k \cdot t)^{2}+\varepsilon\right]^{0.5}}\right)-\mu \cdot\left(\frac{X}{Y_{X / N}}\right)\left[k g_{N} / h \cdot k g_{d . b .}\right]$

In these equations $k$ is the conversion rate from urea to assimilable nitrogen, 0.47 corresponds to urea nitrogen content and $Y_{X / N i}$ is the mass yield between biomass and assimilable nitrogen.

The microorganism consumes starch for growth and maintenance,

$$
\frac{d S}{d t}=-\mu \cdot\left(\frac{X}{Y_{X j S}}\right)-m_{S} \cdot X \quad\left[k g_{S} / h \cdot k g_{d b}\right]
$$

The differential equations for $\mathrm{CO}_{2}$ production and $\mathrm{O}_{2}$ consumption rates include two terms, one associated with growth and the other with maintenance,

$$
\begin{aligned}
& \frac{d \mathrm{CO}_{2}}{d t}=\mu \cdot \frac{X}{Y_{X / \mathrm{CO}_{3}}}+m_{\mathrm{CO}} \cdot X \quad\left[\mathrm{~kg}_{\mathrm{CO}} / \mathrm{h} \cdot \mathrm{kg} g_{b . s}\right] \\
& \frac{d O_{2}}{d t}=\mu \cdot \frac{X}{Y_{X / O_{3}}}+m_{O_{3}} \cdot X \quad\left[k g_{O_{3}} / h \cdot k g_{b . s}\right]
\end{aligned}
$$

where $Y_{X / \mathrm{CO} 2}$ and $Y_{X / O 2}$ are the mass yield coefficients between biomass and respiratory gases.

$\mathrm{GA}_{3}$ net production rate includes a growth associated term with nitrogen inhibition, $\beta$, and a first order degradation rate, $\frac{d G A_{3}}{d t}=\beta \cdot X-k p \cdot G A_{3} \quad\left[k g_{G A_{1}} / h \cdot k g_{d b}.\right]$

The specific growth rate, $\mu$, is modelled using Monod's expression with assimilable nitrogen the limiting nutrient,

$$
\mu=\frac{\mu_{M} N_{I}}{\left(N_{I}+k_{N}\right)} \quad[1 / h]
$$

Here, $\mu_{M}$ is the maximum specific growth rate and $k_{N}$ is the substrate inhibition constant. A substrate inhibition expression describes the specific $\mathrm{GA}_{3}$ production rate,

$$
\beta=\frac{\beta_{M}}{1+k_{i} \cdot N_{I}} \quad\left[k g_{G A_{I}} / k g_{X} \cdot h\right]
$$

where $\beta_{M}$ is the maximum specific $\mathrm{GA}_{3}$ production rate and $k_{i}$ is the associated substrate inhibition constant.

The above model was calibrated in four culture conditions,

i) Temperature $=25^{\circ} \mathrm{C}$, Water Activity $=0.992$.

ii) Temperature $=25^{\circ} \mathrm{C}$, Water Activity $=0.999$.

iii) Temperature $=31^{\circ} \mathrm{C}$, Water Activity $=0.985$.

iv) Temperature $=31^{\circ} \mathrm{C}$, Water Activity $=0.992$.

Further details regarding the experimental set up and the above model are available elsewhere (Gelmi et al. 2000; Gelmi et al. 2002).

\section{Parameter estimation}

We have applied the simultaneous (SimSO) approach to solve the parameter estimation problem. The set of differential equations, $\frac{d y}{d t}=f(y, t)$ represented by is discretized using orthogonal collocation on finite elements. As shown in Figure 1, the integration interval is divided into sub-intervals (finite elements) within which the integration points are located (collocation points).

A differential variable is approximated as a polynomial within a finite element, on a monomial basis (Rice and Duong, 1995).

$$
y_{i}(t)=y_{i-1}+H D(i) \cdot \sum_{q=1}^{n x a l} \Omega\left(\frac{t-t_{i-1}}{H D(i)}\right) \cdot \frac{d y}{d t_{i_{f}}}
$$

where $y_{i-1}$ is the value of the differential variable at the beginning of element $\mathrm{i}, H D(i)$ is the length of element $\mathrm{i}$, $d y / d t_{q, i}$ is the value of the derivative in element $\mathrm{i}$ at the collocation point $q, n \mathrm{col}$ is the number of collocation points 
$\Omega\left(\frac{t-t_{i-1}}{H D(i)}\right)$ satisfying, and is a polynomial of degree ncol,

$$
\begin{aligned}
& \Omega(0)=0 \quad \forall \quad q=1 \cdots n c o l \\
& \Omega^{\prime}(0)=\delta_{q, r} \quad \forall \quad q, r=1 \cdots n c o l
\end{aligned}
$$

Where $\delta_{q, r}$ is the Kronecker delta

$$
\delta_{q,}=l_{q}\left(x_{r}\right)= \begin{cases}0 & q \neq r \\ 1 & q=r\end{cases}
$$

and $l_{q}(x)$ is the basis function for a Lagrange polynomial of order $n c o l$, i.e.,

$$
l_{q}(x)=\prod_{r=1 / \gamma q q}^{n c o l} \frac{\left(x-x_{\gamma}\right)}{\left(x_{q}-x_{\gamma}\right)} \quad \text { and } \quad \Omega_{Q}(t)=\int_{0}^{t} l_{q}(x) d x
$$

We have used 69 finite elements and Radau points with two internal collocation points per finite element, since this configuration achieves a good compromise between precision and efficiency and it is easy to add constraints at the end of each finite element (Rice and Duong, 1995).

Integrating equation [15] with Radau points $\left(T_{1}=\right.$ $\left.0.1550625 ; T_{2}=0.6449948 ; T_{3}=1\right)$, and $t_{i, q}=t_{i-1}+$ $H D(i) \cdot T_{q}$, leads to values for the polynomial coefficients, $\mathrm{W}\left(t_{i, q}\right)$.

$$
y_{i, k}=y\left(t_{i, k}\right)+H D(i) \sum_{q=1}^{n c o l} \Omega\left(\tau_{k}\right) \frac{d y}{d t_{i, q}}
$$

$$
\text { with } \frac{d y}{d t_{i_{A}}}=f\left(y_{i_{A}}, t_{i_{A}}\right)
$$

The system [15] approximates the differential variable over the respective finite element. To solve the differential equations over the entire time domain, we expand these equations for each finite element and collocation point. This large set of nonlinear algebraic equations represents a high-order implicit Runge-Kutta (IRK) approximation to the differential equations.

The model parameters were estimated by weighted least squares,
$\operatorname{Min} \sum_{i=1}^{n}\left\{\sum_{k_{t}=0}^{K_{t}-1}\left[\frac{y_{i}\left(k_{i} \cdot \Delta t_{i}\right)-\hat{y}_{i}\left(k_{i} \cdot \Delta t_{i}\right)}{K_{i} \cdot \bar{y}_{i}}\right]^{2}\right\}$

Subject to,

$$
\begin{aligned}
& \frac{d \hat{\mathbf{y}}}{d t}=\mathbf{f}(\hat{\mathbf{y}}, \hat{\mathbf{\theta}}) \\
& \mathbf{g}(\hat{\mathbf{y}}, \hat{\mathbf{\theta}})=0 \\
& \mathbf{\theta}_{L} \leq \hat{\mathbf{\theta}} \leq \mathbf{\theta}_{U} \\
& 0 \leq y_{i} \quad \forall i=1, \cdots, n[18]
\end{aligned}
$$

where $n$ is the number of measured variables and $K_{i}, \Delta t_{i}, \hat{y}_{i}$ and $y$ are the number of measured values, the sampling interval, the solution of the differential equation and the normalization value for variable $y_{i}$, respectively. The vector of estimated parameters is represented by $\hat{\boldsymbol{\theta}}$.

Because parameter $k$ appears only in equations (3-5), and has little influence on the remaining state variables, it is estimated separately and can be obtained directly from the urea consumption curve. In addition, it was also verified that parameters $m_{M}$ and $k_{N}$ in equation [9] are correlated, since many combinations of these parameter values achieved the same data fit. Thus, we obtained the values of $m_{M}$ from curves of the accumulated respiratory gases (Saucedo-Castañeda et al. 1994), and estimated $k_{N}$ using the least squares procedure described above. The values obtained of both rates $\left(k\right.$ and $\left.m_{M}\right)$ for all cultivation conditions are given in Table 1.

The vector of estimated parameters, therefore, through least squares using equations 17 and 18 is $\theta=\left(k_{i}, k_{N}, k_{P}, m_{C O 2}\right.$, $\left.m_{O 2}, m_{S}, K_{D}, Y_{X / C O 2}, Y_{X / O 2}, Y_{X / N}, Y_{X / S}, \beta_{M}\right)^{\prime}$. The resulting large scale optimization problem was solved in AMPL using IPOPT solver (Biegler et al. 2002).

Results obtained with the procedure described above were compared with those obtained with the SeqSO approach, as described in Gelmi et al. (2002).

\section{Statistical analysis}

Once the optimization is carried out, the solution of $(17,18)$ can be formally written as $\hat{y}=F(\hat{\boldsymbol{\theta}})$, where $\hat{y}$ is the numerical solution of the differential equations $(1-11)$. At this point we add further computations, explained next, to estimate the parameters' standard deviations $\left(\sigma_{\theta i}\right)$. First, we compute numerically the Jacobian $\mathrm{J}$ of the numerical solution with respect to the optimized parameters: $\mathrm{J}=$ $(\delta \mathrm{F} / \delta \theta)$ at the point $\theta=\hat{\mathbf{\theta}}$. We do this in MATLAB using numerical integration for constructing the solution $F$ for 
different perturbations $\Delta \theta$ of the $\theta$ parameters and then using central finite differences to estimate the Jacobian by,

$$
\hat{\mathbf{J}}(\hat{\theta})=\frac{\mathbf{F}(\hat{\boldsymbol{\theta}}+\Delta \boldsymbol{\theta})-\mathbf{F}(\hat{\boldsymbol{\theta}}-\Delta \boldsymbol{\theta})}{2 \Delta \boldsymbol{\theta}}+O\left((\Delta \boldsymbol{\theta})^{2}\right)
$$

We have found that using $\Delta \theta=0.001 \theta$ is sufficient to obtain accurate estimates of the Jacobian.

Now, since the number (n) of experimental points is large enough $\left(\mathrm{O}\left(10^{3}\right)\right)$, we can use the linear approximation (Seber and Wild, 1998) to use the result:

$$
\hat{\mathbf{\theta}}-\boldsymbol{\theta}^{*} \approx N_{P}\left(0, \boldsymbol{\sigma}^{2} \mathbf{C}^{-1}\right) ; \quad \mathbf{C}=\mathbf{J}\left(\boldsymbol{\theta}^{*}\right)^{T} \cdot \mathbf{J}\left(\boldsymbol{\theta}^{*}\right)
$$

Where $\theta^{*}$ is the true parameter vector, $\hat{\boldsymbol{\theta}}$ its estimated value and $\sigma^{2}$ is the variance of model residuals when the model is integrated using $\theta^{*}$. Now, according to standard procedures (Seber and Wild, 1989), we have used the Jacobian and error variance evaluated at $\hat{\boldsymbol{\theta}}$ to construct the variance/covariance matrix estimate $\mathrm{s}^{2}(\hat{\mathrm{C}})^{-1}$, where $\mathrm{s}^{2}=\| \hat{\mathrm{y}}$ $\mathrm{y}_{\mathrm{OBS}} \|^{2} /(\mathrm{n}-\mathrm{p})$ is an unbiased estimate of $\sigma^{2}$, with yoBs the vector of observed values, and $p$ is the number of estimated parameters. Parameter standard deviations $\left(\sigma_{\theta i}\right)$ are estimated as the square roots of the variance/covariance matrix diagonal. The ratio $\theta_{\mathrm{i}} /\left(\sigma_{\theta i}\right)$ is called the $\mathrm{t}$-value for $\theta_{\mathrm{i}}$ because it follows a t-distribution with (n-p) degrees of freedom (Seber and Wild, 1989). For large values of (n-p), as in our cases, $t$-values larger than 2.0 mean that the $95 \%$ confidence interval for $\theta_{i}$ does not include the zero value, that is, the parameter $\theta_{\mathrm{i}}$ is statistically significant.

\section{RESULTS AND DISCUSSION}

We compare our calibration results for each cultivation condition with the fit obtained using the SeqSO approach. We were specifically interested in fit quality, the performance of the optimization procedure and the value and accuracy of the estimated parameters.

\section{Cultivation condition $1\left(T=25^{\circ} \mathrm{C}, \mathrm{a}_{\mathrm{w}}=0.992\right)$}

In Table 2 we can see that the SimSO estimation of the $\mathrm{GA}_{3}$ inhibition constant, $k_{i}$, was highly inaccurate (large $\sigma$ ) yet the parameter is significant; the SimSO estimation of the $\mathrm{GA}_{3}$ degradation rate constant, $k_{p}$, was unreliable ( $\mathrm{t}$ value is almost zero). Therefore, it is pointless to compare the two methods' estimation of these parameters. Other parameter estimates were reliable ( $\mathrm{t}$ values above 2 ) and accurate (relatively small $\sigma$ ). We don't have the estimation of $\sigma$ for the parameters obtained with the SeqSO calibration method. Therefore, if we assume that both methods yield the same $\sigma$ it is reasonable, as a first approximation, to consider that both parameter estimates are similar when their difference is smaller than 3 times the standard deviation computed for the SimSO estimate (Wild and
Seber, 2000). Then, in this cultivation using the two fitting condition four parameter estimates differed significantly methods, the Monod's constant in equation [10], $k_{N}$, the biomass/oxygen yield coefficient, $Y_{X / O 2}$, the biomass/nitrogen yield coefficient, $Y_{X N}$, and the maximum specific $\mathrm{GA}_{3}$ production rate, $\beta_{M}$.

We should expect therefore model simulations with both parameter sets to be similar. This supposition is supported by a marginal improvement in the objective function (equation 17) (see Table 3). Hence, the SimSO method shows only a slightly better fit for the respiratory gases (Figure 2) and the other model variables are almost indistinguishable for the two methods (not shown).

For the particular conditions of cultivation 1, the main advantage of the SimSO calibration procedure is its efficiency and robustness. We started from two different guesses and achieved the same estimation parameters in less than $30 \mathrm{CPU} \mathrm{s}$ on an Athlon XP $2 \mathrm{~K}$ PC, running Windows XP. Here, deviation errors in equation [17] were normalized by the maximum measured value.

\section{Cultivation condition $2\left(T=25^{\circ} \mathrm{C}, a_{w}=0.999\right)$}

Under these conditions there was an unusual delay of $20 \mathrm{hrs}$ in microorganism growth, which the model does not consider. Hence, calibration only included the data after 20 hrs. Estimates for $k_{i}$ and $k_{P}$ were not significant (t value below 2); most of the other parameter estimates were very significant (t above 10), as shown in Table 4. The SimSO fit presented estimated parameter values different from the SeqSO method, except for the death rate constant, $K_{D}$, the biomass/nitrogen yield coefficient, $Y_{X / N}$, and the oxygen maintenance coefficient, $m_{\mathrm{O} 2}$.

Despite the differences in parameter values observed in Table 4, only oxygen consumption and $\mathrm{GA}_{3}$ production curves differed significantly in fittings with the two methods (Figure 3). Moreover, the objective function value of the SimSO calibration is just $10 \%$ lower than the SeqSO result (Table 3).

Here, deviation errors in the objective function were also normalized by the maximum measured value. Since starting from two different guesses produced the same set of estimates in less than $30 \mathrm{sec}$, just like in the fitting of condition 1, the SimSO calibration procedure for this data was efficient and robust.

\section{Cultivation condition $3\left(\mathrm{~T}=31^{\circ} \mathrm{C}, \mathrm{a}_{\mathrm{w}}=\mathbf{0 . 9 8 5}\right)$}

Table 5 shows that under these conditions, the $k_{P}$ SimSO estimate was not significant. However, contrary to cultivation conditions 1 and 2 , the $k_{i}$ estimate was significant and more accurate; at least here, contrary to cultivations 1 and 2, $\sigma$ for this parameter is smaller than the estimate values allowing us to compare both methods. Again, the rest of the parameter estimates were significant 
and accurate. Table 5 shows that both methods yielded different estimates for all model parameters, except for the death rate constant, $K_{D}$. Moreover, a much better fit was achieved with SimSO parameter values for biomass, $\mathrm{GA}_{3}$ and starch (Figure 4) that, in turn, is reflected in the sharp reduction in the objective function (Table 3). Here, again, deviation errors were normalized by the maximum measured value and optimization was started from two different initial guesses. Convergence was more difficult than for the previous cultivation conditions, requiring more iterations and CPU time (Table 3).

\section{Cultivation condition $4\left(\mathrm{~T}=31^{\circ} \mathrm{C}, \mathrm{a}_{\mathrm{w}}=0.992\right)$}

Here, $k_{i}$ and $k_{P}$ estimates were not significant, while the remaining SimSO parameter estimates were accurate and significant (Table 6). Except for $m_{\mathrm{CO} 2}, Y_{X / \mathrm{CO} 2}$ and $Y_{X / N}$, SimSO parameter estimates did not stray much from the SeqSO estimates. Nevertheless, the SimSO procedure achieved a better fit for biomass and $\mathrm{GA}_{3}$ (Figure 5), and a significantly lower objective function value (Table 3 ). Convergence for these conditions was the most difficult of the 4 cases, requiring a 5-fold increase in CPU time than in cultivation conditions 1 and 2 (Table 3 ) and twice as much as cultivation 3 . We had to normalize by the average measured value in equation [17] to get convergence here, too.

\section{Effect of temperature}

In a comparison of cultivation conditions 1 and 4 only the death rate was unaffected by temperature (Table 2 and Table 6). The other model parameters took on different values at the two temperatures. For instance, $\mu_{M}, \beta_{M}$ and the maintenance coefficients increased with temperature, while the yield coefficients and $k_{N}$ decreased with temperature (Table 1, Table 2 and Table 6). The net result was that at $25^{\circ} \mathrm{C}$ twice as much biomass was produced, while a little more $\mathrm{GA}_{3}$ was produced at $31^{\circ} \mathrm{C}$ (results not shown). In addition, at $25^{\circ} \mathrm{C}$ production of $\mathrm{CO}_{2}$ and consumption of $\mathrm{O}_{2}$ was a bit higher (results not shown).

\section{Effect of water activity}

Comparing cultivation conditions 1 and 2, we observe that, except for $m_{S}$, water activity had little effect on the maintenance coefficients. Yield coefficients, $\mu_{M}$ and $\beta_{M}$ were higher for $a_{w}=0.992$, while $k_{N}$ and $K_{D}$ were lower (Table 1, Table 2 and Table 4). The net result was that for $a_{w}=0.992$ around $30 \%$ more biomass and twice as much $\mathrm{GA}_{3}$ were produced (results not shown). Comparing cultivations 3 and 4 , on the other hand, we observe that for $a_{w}=0.985$ the death rate was unaffected, $k_{N}, \beta_{M}$ and maintenance coefficients were higher, while the yield coefficients and $\mu_{M}$ were lower (Table 1, Table 5 and Table 6). Therefore, for $a_{w}=0.985$ less biomass and a little more $\mathrm{GA}_{3}$ were obtained (results not shown).
Overall, estimation of $\mathrm{GA}_{3}$ kinetic parameters proved awkward. Estimations of $k_{p}$ were unreliable and close to zero for all cultivation conditions, and indicates that $\mathrm{GA}_{3}$ degradation in these experiments was most probably negligible. Moreover, estimations of $k_{i}$ were unreliable or inaccurate in almost all instances. $\mathrm{GA}_{3}$ is a secondary metabolite that Gibberella starts producing when available nitrogen in the medium is almost exhausted. Therefore, many measurements close to the point of nitrogen exhaustion are required to obtain accurate estimations of $k_{i}$. In the range studied, we also verified that $\beta_{M}$ increases with temperature yet it decreases with water activity. Regarding variations of growth kinetic parameters, we found the death rate was unaffected by temperature and reached a maximum for $a_{w}=0.999$. In addition, $\mu_{M}$ increased with temperature and water activity, while $k_{N}$ decreased with temperature and it appeared to reach a minimum at $a_{w}=$ 0.992. Maintenance coefficients increased with temperature and took their highest values at $a_{w}=0.985$. In turn, yield coefficients decreased with temperature and appeared to reach their maximum at $a_{w}=0.992$.

The importance of this work is the significant reduction in convergence time the SimSO approach achieved. As a consequence it drastically simplified the parameter estimation problem. A typical calibration with the SeqSO approach, as described in Gelmi et al. (2002), required many runs of the optimization program, each taking several hours to converge and requiring a high degree of heuristics and, in all, the entire SeqSO procedure took over a week to complete. Another important consideration is that for most conditions the SimSO calibration strategy achieved a significantly better fit for biomass, $\mathrm{GA}_{3}$ and oxygen consumption. The method used here is a valuable tool and should contribute appreciably to the development and testing of complex SSF mechanistic models.

\section{ACKNOWLEDGMENTS}

The authors thank Alex Crawford for his assistance in improving the style of the text.

\section{REFERENCES}

BIEGLER, Lorenz T.; CERVANTES, Arturo M. and WÄCHTER, Andreas. Advances in simultaneous strategies for dynamic process optimization. Chemical Engineering Science, February 2002, vol. 57, no. 4, p. 575-593.

CORONA, Andrés; SÁEZ, Doris and AGOSIN, Eduardo. Effect of water activity on gibberellic acid production by Gibberella fujikuroi under solid-state fermentation conditions. Process Biochemistry, July 2005, vol. 40, no. 8, p. 2655-2658.

GELMI, Claudio; PÉREZ-CORREA, Ricardo; GONZÁLEZ, M. and AGOSIN, Eduardo. Solid substrate cultivation of Gibberella fujikuroi on an inert support. 
Process Biochemistry, July 2000, vol. 35, no. 10, p. 1227 1233.

GELMI, Claudio; PÉREZ-CORREA, Ricardo and AGOSIN, Eduardo. Modelling Gibberella fujikuroi growth and $\mathrm{GA}_{3}$, production in solid-state fermentation. Process Biochemistry, April 2002, vol. 37, no. 9, p. 1033-1040.

HÖLKER, Udo and LENZ, Jürgen. Solid-state fermentation - are there any biotechnological advantages? Current Opinion in Microbiology, June 2005, vol. 8, no. 3, p. 301-306.

JIAN, $\mathrm{Xu} ; \mathrm{SHOUWEN,}$ Chen and ZINIU, Yu. Optimization of process parameters for poly $\gamma$ glutamate production under solid state fermentation from Bacillus subtilis CCTCC202048. Process Biochemistry, September 2005, vol. 40, no. 9, p. 3075-3081.

JOHN, Rojan P.; NAMPOOTHIRI, K. Madhavan and PANDEY, Ashok. Solid-state fermentation for L-lactic acid production from agro wastes using Lactobacillus delbrueckii. Process Biochemistry, April 2006, vol. 41, no. 4, p. 759-763.

KRASNIEWSKI, Isabelle; MOLIMARD, Pascal; FERON, Gilles; VERGOIGNAN, Catherine; DURAND, Alain; CAVIN, Jean-François and COTTON, Pascale. Impact of solid medium composition on the conidiation in Penicillium Camemberti. Process Biochemistry, June 2006, vol. 41, no. 6, p. 1318-1324.

LECHNER, B.E. and PAPINUTTI, V.L. Production of lignocellulosic enzymes during growth and fruiting of the edible fungus Lentinus tigrinus on wheat straw. Process Biochemistry, March 2006, vol. 41, no. 3, p. 594-598.

MACHADO, Cristina M.M.; OISHI, Bruno O.; PANDEY, Ashok and SOCCOL, Carlos R. Kinetics of Gibberella fujikuroi growth and gibberellic acid production by solidstate fermentation in a packed-bed column bioreactor. Biotechnology Progress, September 2004, vol. 20, no. 5, p. 1449-1453.

MITCHELL, David A.; VON MEIEN, Oscar F.; KRIEGER, Nadia and DALSENTER, Farah Diba H. A review of recent developments in modeling of microbial growth kinetics and intraparticle phenomena in solid-state fermentation. Biochemical Engineering Journal, January 2004, vol. 17, no. 1, p. 15-26.

PANDEY, Ashok. Solid-state fermentation. Biochemical Engineering Journal, March 2003, vol. 13, no. 2-3, p. 8184.

RICE, Richard G. and DUONG, Do D. Applied mathematics and modeling for chemical engineers. New York, John Wiley and Sons, Inc., 1995. 719 p. ISBN 0-47130377-1.
RIVERA, Elmer Copa; COSTA, Aline C.; ATALA, Daniel I.P.; MAUGERI, Francisco; WOLF MACIEL, Maria R. and MACIEL FILHO, Rubens. Evaluation of optimization techniques for parameter estimation: Application to ethanol fermentation considering the effect of temperature. Process Biochemistry, July 2006, vol. 41, no. 7, p. 1682-1687.

SABU, A.; AUGUR, C.; SWATI, C. and PANDEY, A. Tannase production by Lactobacillus sp. ASR-S1 under solid-state fermentation. Process Biochemistry, March 2006, vol. 41, no. 3, p. 575-580.

SAUCEDO-CASTAÑEDA, G.; TREJO-HERNÁNDEZ, M.R.; LONSANE, B.K.; NAVARRO, J.M.; ROUSSOS, S.; DUFOUR, D. and RAIMBAULT, M. On-line automated monitoring and control systems for $\mathrm{CO}_{2}$ and $\mathrm{O}_{2}$ in aerobic and anaerobic solid-state fermentations. Process Biochemistry, 1994, vol. 29, no. 1, p. 13-24.

SEBER, G.A.F. and WILD, C.J. Nonlinear Regression. New York, John Wiley and Sons, Inc., 1989. 800 p. ISBN 0-471-47135-6.

WILD, C.J and SEBER, G.A.F. Chance encounters: A first course in data analysis and inference. New York, Wiley and Sons, Inc., 2000. 632 p. ISBN 0-471-32936-3. 


\section{APPENDIX}

TABLES

Table 1. Urea decomposition rate $(k)$ and maximum specific growth rate $\left(m_{M}\right)$ estimated from urea consumption curves and from the accumulated respiratory gases (for all cultivation conditions), respectively.

\begin{tabular}{|c|c|c|c|}
\hline $\begin{array}{c}\mathbf{T} \\
\left.\mathbf{(}^{\circ} \mathbf{C}\right)\end{array}$ & $\mathbf{a}_{\mathbf{w}}$ & $\begin{array}{c}\boldsymbol{k} \mathbf{1 0}^{\mathbf{4}} \\
(\mathbf{1 / h})\end{array}$ & $\begin{array}{c}\mathbf{m}_{\mathbf{M}} \\
(\mathbf{1} / \mathbf{h})\end{array}$ \\
\hline 25 & 0.992 & 1.287 & 0.1832 \\
\hline 25 & 0.999 & 3.529 & 0.2253 \\
\hline 31 & 0.985 & 1.553 & 0.1868 \\
\hline 31 & 0.992 & 1.243 & 0.1968 \\
\hline
\end{tabular}

Table 2. Estimates and statistical parameters for cultivation condition 1.

\begin{tabular}{|c|c|c|c|c|}
\hline & SeqSO & \multicolumn{3}{|c|}{ Simso } \\
\hline $\boldsymbol{\theta}$ & Value & Value & $\sigma$ & t-val \\
\hline$k_{i}$ & $3 \mathrm{E}+05$ & $8 \mathrm{E}+05$ & $3 \mathrm{E}+05$ & $3 \mathrm{E}+00$ \\
\hline$k_{N}$ & $7.9 \mathrm{E}-04$ & $4.6 \mathrm{E}-04$ & $1 \mathrm{E}-05$ & $4 \mathrm{E}+01$ \\
\hline$k_{P}$ & $2 \mathrm{E}-03$ & $4 \mathrm{E}-09$ & $8 \mathrm{E}-04$ & $6 \mathrm{E}-06$ \\
\hline$m_{C O 2}$ & $1.32 \mathrm{E}-01$ & $1.32 \mathrm{E}-01$ & $5 \mathrm{E}-03$ & $3 \mathrm{E}+01$ \\
\hline$m_{O 2}$ & $5.5 \mathrm{E}-02$ & $5.4 \mathrm{E}-02$ & $2 \mathrm{E}-03$ & $3 \mathrm{E}+01$ \\
\hline$m_{S}$ & $9 \mathrm{E}-02$ & $9.9 \mathrm{E}-02$ & $7 \mathrm{E}-03$ & $1 \mathrm{E}+01$ \\
\hline$K_{D}$ & $2.66 \mathrm{E}-02$ & $2.43 \mathrm{E}-02$ & $6 \mathrm{E}-04$ & $4 \mathrm{E}+01$ \\
\hline$Y_{X / C O 2}$ & $1.2 \mathrm{E}+00$ & $1.8 \mathrm{E}+00$ & $3 \mathrm{E}-01$ & $6 \mathrm{E}+00$ \\
\hline$Y_{X / O 2}$ & $2.6 \mathrm{E}+00$ & $3.7 \mathrm{E}+00$ & $5 \mathrm{E}-01$ & $7 \mathrm{E}+00$ \\
\hline$Y_{X / N}$ & $2.10 \mathrm{E}+01$ & $2.03 \mathrm{E}+01$ & $3 \mathrm{E}-01$ & $8 \mathrm{E}+01$ \\
\hline$Y_{X / S}$ & $9 \mathrm{E}-01$ & $1.4 \mathrm{E}+00$ & $5 \mathrm{E}-01$ & $3 \mathrm{E}+00$ \\
\hline$\beta_{M}$ & $6.1 \mathrm{E}-04$ & $4.5 \mathrm{E}-04$ & $2 \mathrm{E}-05$ & $3 \mathrm{E}+01$ \\
\hline
\end{tabular}


Table 3. Numerical performance of the optimization with both methods for all cultivation conditions.

\begin{tabular}{|c|c|c|c|}
\hline Cultivation \# (method) & Cost function (Eq. 17) & Iter. & CPU (s) \\
\hline 1 (SeqSO) & 0.035 & - & - \\
\hline 1 (SimSO) & 0.032 & 198 & $29.7^{\text {(a) }}$ \\
\hline 2 (SeqSO) & 0.092 & - & - \\
\hline 2 (SimSO) & 0.088 & 441 & $28.5^{(\mathrm{b})}$ \\
\hline 3 (SeqSO) & 0.047 & - & - \\
\hline 3 (SimSO) & 0.035 & 891 & $74.3^{(\mathrm{a})}$ \\
\hline 4 (SeqSO) & 0.141 & - & - \\
\hline 4 (SimSO) & 0.089 & 852 & $149^{(\mathrm{a})}$ \\
\hline
\end{tabular}

(a) Athlon XP, running Windows XP.

(b) NEOS server: http://www-neos.mcs.anl.gov/neos/solvers/NCO:IPOPT/solver-www.html.

Table 4. Estimates and statistical parameters for cultivation condition 2.

\begin{tabular}{|c|c|c|c|c|}
\hline \multirow[b]{2}{*}{$\theta$} & \multirow{2}{*}{$\begin{array}{c}\text { SeqSO } \\
\text { Value }\end{array}$} & \multicolumn{3}{|c|}{ Simso } \\
\hline & & Value & $\sigma$ & t-val \\
\hline$k_{i}$ & $2 E+05$ & $1 E+03$ & $1 E+03$ & $1 E+00$ \\
\hline$k_{N}$ & $4.7 E-04$ & $6.3 E-04$ & $3 E-05$ & $2 E+01$ \\
\hline$k_{P}$ & $O E+00$ & $2 E-08$ & $1 E-03$ & $1 E-05$ \\
\hline$m_{\mathrm{CO} 2}$ & 1.65E - 01 & $1.25 \mathrm{E}-01$ & $9 E-03$ & $1 E+01$ \\
\hline$m_{\mathrm{O} 2}$ & $7.2 E-02$ & $5.9 E-02$ & 4E - 03 & $1 E+01$ \\
\hline$m_{S}$ & $8 E-02$ & $4 E-02$ & $1 E-02$ & $3 E+00$ \\
\hline$K_{D}$ & $3.9 E-02$ & $3.3 E-02$ & $2 E-03$ & $2 E+01$ \\
\hline$Y_{X / C O 2}$ & $1.96 E+00$ & $7.9 \mathrm{E}-01$ & $7 E-02$ & $1 E+01$ \\
\hline$Y_{X / O 2}$ & $3.8 E+00$ & $2.4 \mathrm{E}+00$ & $3 E-01$ & $8 E+00$ \\
\hline$Y_{X / N}$ & $1.7 E+01$ & $1.7 E+01$ & $3 E-01$ & $5 E+01$ \\
\hline$Y_{X / S}$ & 1.83E - 01 & $1.51 E-01$ & $8 E-03$ & $2 E+01$ \\
\hline$\beta_{M}$ & $5.6 E-04$ & $2.8 \mathrm{E}-04$ & 4E - 05 & $8 E+00$ \\
\hline
\end{tabular}


Table 5. Estimates and statistical parameters for cultivation condition 3.

\begin{tabular}{|c|c|c|c|c|}
\hline & SeqSO & \multicolumn{2}{|c|}{ SimsO } \\
\hline $\boldsymbol{\theta}$ & Value & Value & $\sigma$ & t-val \\
\hline$k_{i}$ & $9.530 \mathrm{E}+06$ & $1.9 \mathrm{E}+04$ & $7 \mathrm{E}+03$ & $3 \mathrm{E}+00$ \\
\hline$k_{N}$ & $3.0 \mathrm{E}-04$ & $7.7 \mathrm{E}-04$ & $2 \mathrm{E}-05$ & $4 \mathrm{E}+01$ \\
\hline$k_{P}$ & $0 \mathrm{E}+00$ & $4 \mathrm{E}-10$ & $1 \mathrm{E}-03$ & $40 \mathrm{E}-07$ \\
\hline$m_{C O 2}$ & $4.3 \mathrm{E}-01$ & $2.4 \mathrm{E}-01$ & $1 \mathrm{E}-02$ & $2 \mathrm{E}+01$ \\
\hline$m_{O 2}$ & $2.40 \mathrm{E}-01$ & $1.50 \mathrm{E}-01$ & $7 \mathrm{E}-03$ & $2 \mathrm{E}+01$ \\
\hline$m_{S}$ & $9.0 \mathrm{E}-01$ & $3.3 \mathrm{E}-01$ & $4 \mathrm{E}-02$ & $8 \mathrm{E}+00$ \\
\hline$K_{D}$ & $2.70 \mathrm{E}-02$ & $2.71 \mathrm{E}-02$ & $9 \mathrm{E}-04$ & $3 \mathrm{E}+01$ \\
\hline$Y_{X / C O 2}$ & $7.45 \mathrm{E}-01$ & $1.71 \mathrm{E}-01$ & $7 \mathrm{E}-03$ & $3 \mathrm{E}+01$ \\
\hline$Y_{X / O 2}$ & $1.22 \mathrm{E}+00$ & $3.8 \mathrm{E}-01$ & $2 \mathrm{E}-02$ & $3 \mathrm{E}+01$ \\
\hline$Y_{X / N}$ & $5.0 \mathrm{E}+00$ & $6.3 \mathrm{E}+00$ & $1 \mathrm{E}-01$ & $5 \mathrm{E}+01$ \\
\hline$Y_{X / S}$ & $1.01 \mathrm{E}-01$ & $4.3 \mathrm{E}-02$ & $2 \mathrm{E}-03$ & $2 \mathrm{E}+01$ \\
\hline$\beta_{M}$ & $3.1 \mathrm{E}-03$ & $2.4 \mathrm{E}-03$ & $3 \mathrm{E}-04$ & $9 \mathrm{E}+00$ \\
\hline & & & & \\
\hline
\end{tabular}

Table 6. Estimates and statistical parameters for cultivation condition 4.

\begin{tabular}{|c|c|c|c|c|}
\hline & SeqSO & \multicolumn{3}{|c|}{ SimsO } \\
\hline $\boldsymbol{\theta}$ & Value & Value & $\sigma$ & t-val \\
\hline$k_{i}$ & $1 \mathrm{E}+05$ & $1 \mathrm{E}+07$ & $3 \mathrm{E}+07$ & $3 \mathrm{E}-01$ \\
\hline$k_{N}$ & $2.4 \mathrm{E}-04$ & $2.6 \mathrm{E}-04$ & $2 \mathrm{E}-05$ & $2 \mathrm{E}+01$ \\
\hline$k_{P}$ & $0 \mathrm{E}+00$ & $1 \mathrm{E}-09$ & $1 \mathrm{E}-03$ & $1 \mathrm{E}-06$ \\
\hline$m_{\mathrm{CO} 2}$ & $2.44 \mathrm{E}-01$ & $1.96 \mathrm{E}-01$ & $7 \mathrm{E}-03$ & $3 \mathrm{E}+01$ \\
\hline$m_{\mathrm{O} 2}$ & $1.15 \mathrm{E}-01$ & $1.02 \mathrm{E}-01$ & $4 \mathrm{E}-03$ & $3 \mathrm{E}+01$ \\
\hline$m_{S}$ & $2.1 \mathrm{E}-01$ & $1.7 \mathrm{E}-01$ & $2 \mathrm{E}-02$ & $8 \mathrm{E}+00$ \\
\hline$K_{D}$ & $2.50 \mathrm{E}-02$ & $2.47 \mathrm{E}-02$ & $8 \mathrm{E}-04$ & $3 \mathrm{E}+01$ \\
\hline$Y_{X / C O 2}$ & $1.73 \mathrm{E}+00$ & $6.7 \mathrm{E}-01$ & $7 \mathrm{E}-02$ & $1 \mathrm{E}+01$ \\
\hline$Y_{X / O 2}$ & $2.6 \mathrm{E}+00$ & $2.0 \mathrm{E}+00$ & $4 \mathrm{E}-01$ & $6 \mathrm{E}+00$ \\
\hline$Y_{X / N}$ & $9.6 \mathrm{E}+00$ & $1.06 \mathrm{E}+01$ & $2 \mathrm{E}-01$ & $4 \mathrm{E}+01$ \\
\hline$Y_{X / S}$ & $1.8 \mathrm{E}-01$ & $1.8 \mathrm{E}-01$ & $2 \mathrm{E}-02$ & $1 \mathrm{E}+01$ \\
\hline$\beta_{M}$ & $8.8 \mathrm{E}-04$ & $9.1 \mathrm{E}-04$ & $9 \mathrm{E}-05$ & $1 \mathrm{E}+01$ \\
\hline
\end{tabular}




\section{FIGURES}

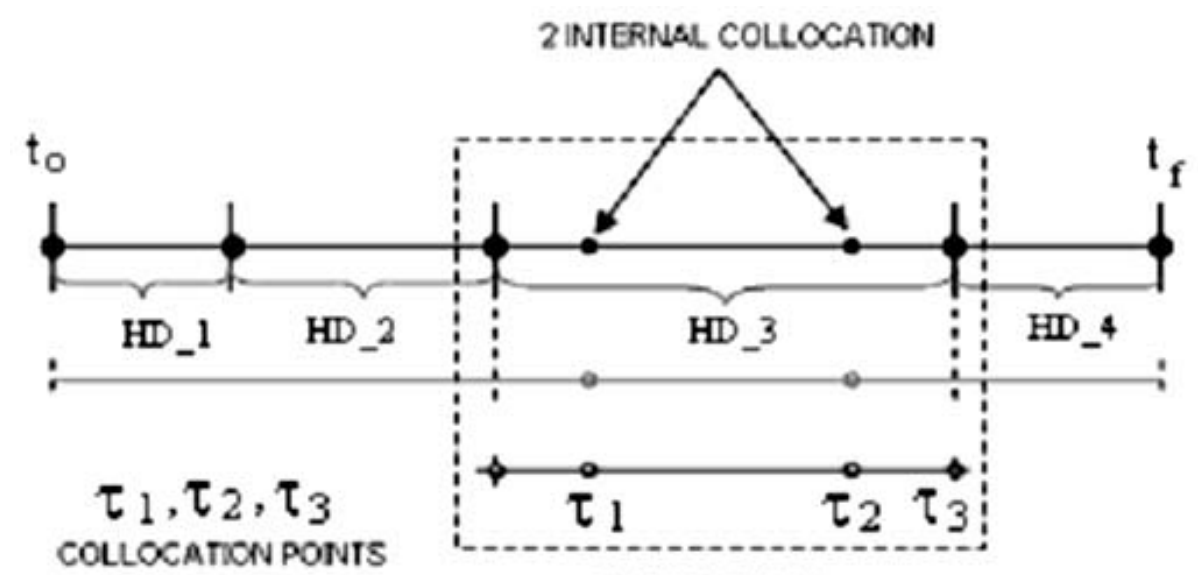

FDITE ELEMENT

Figure 1. Finite elements and collocation points.
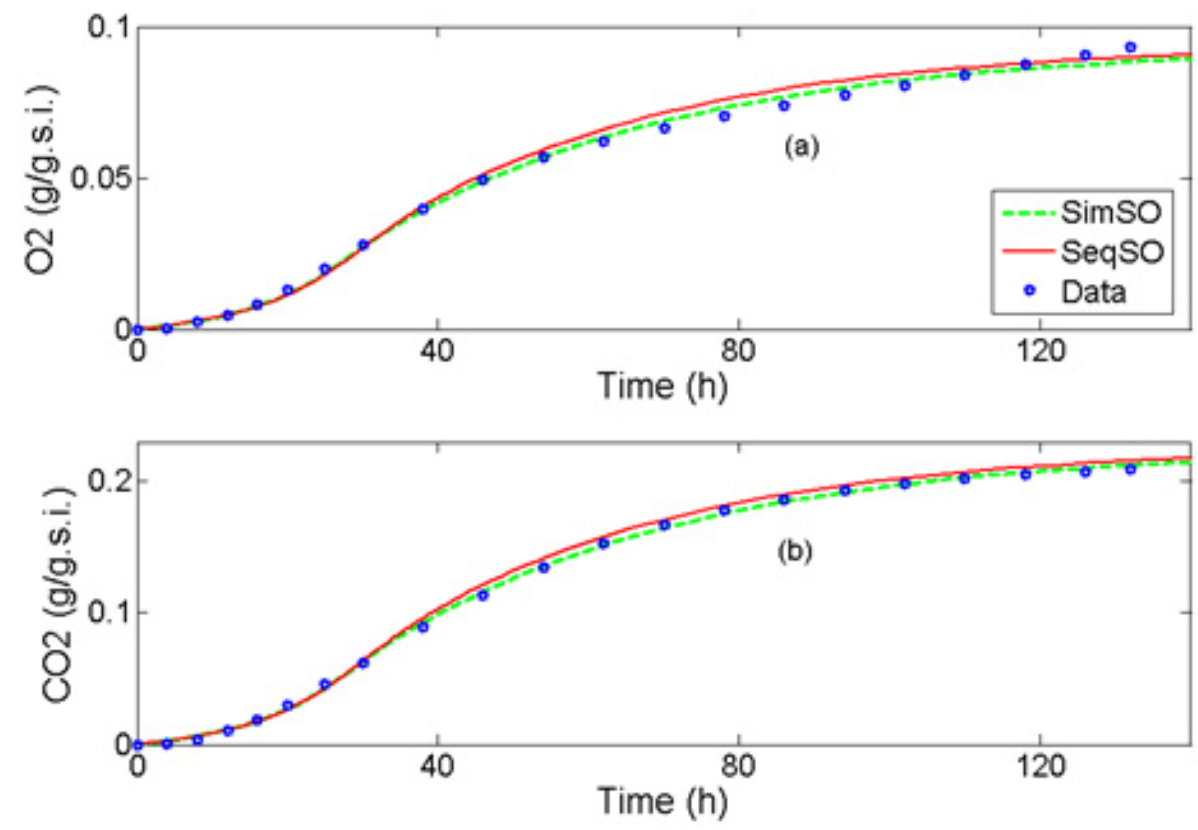

Figure 2. Model performance with optimal parameter estimates for cultivation condition $1\left(25^{\circ} \mathrm{C}\right.$ and 0.992). 

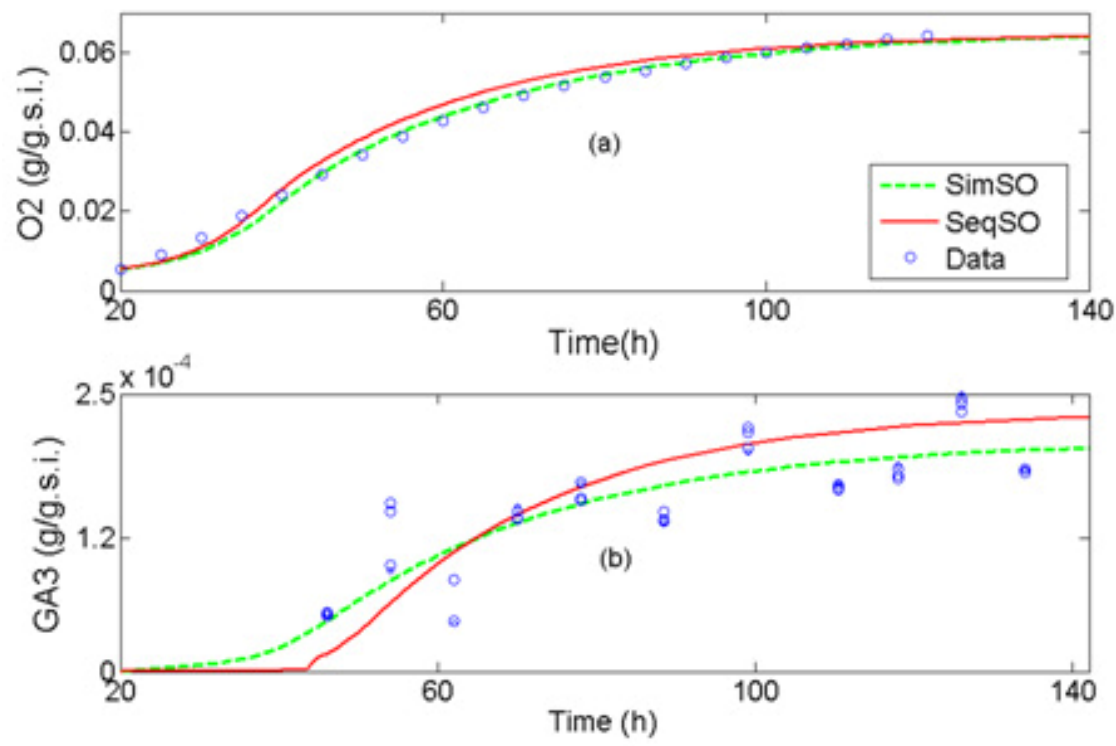

Figure 3. Model performance with optimal parameter estimates for cultivation condition $2\left(25^{\circ} \mathrm{C}\right.$ and 0.999). The Simso problem was solved with an earlier version of IPOPT (http://wwwneos.mcs.anl.gov/neos/solvers/NCO:IPOPT/solver-www.html).
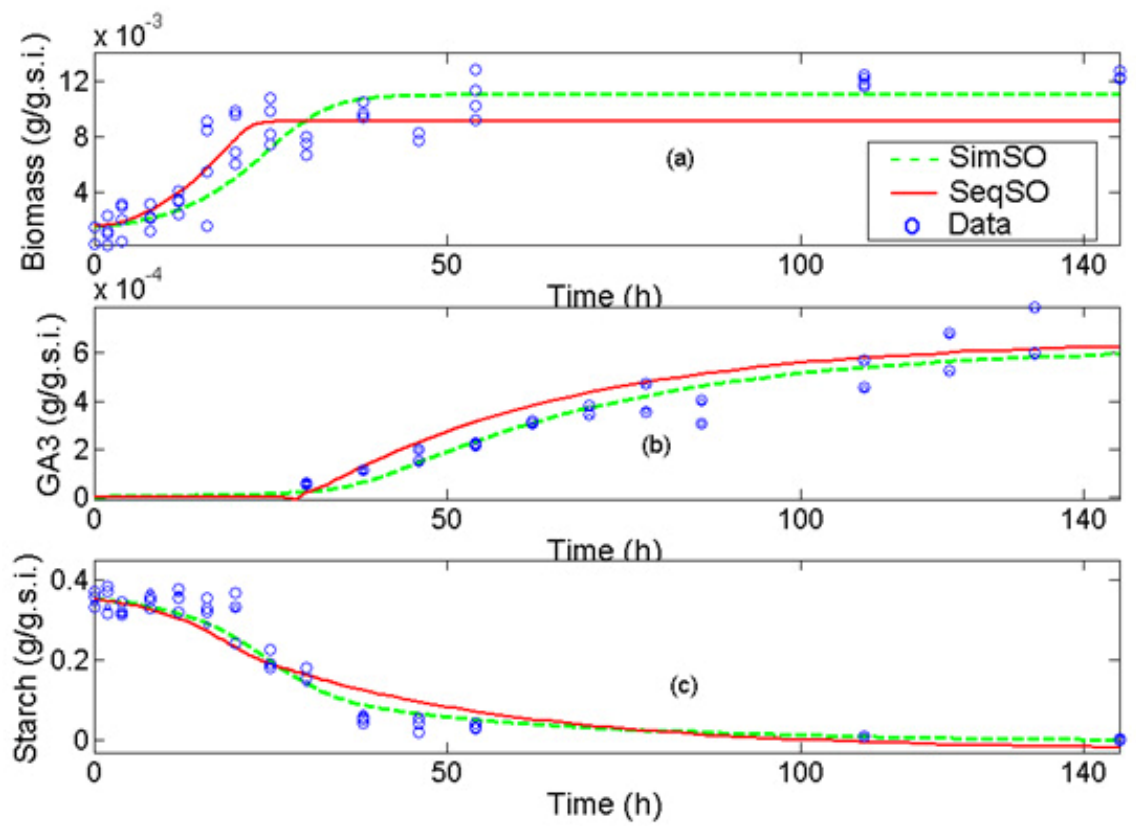

Figure 4. Model performance with optimal parameter estimates for cultivation condition $3\left(31^{\circ} \mathrm{C}\right.$ and 0.985). 

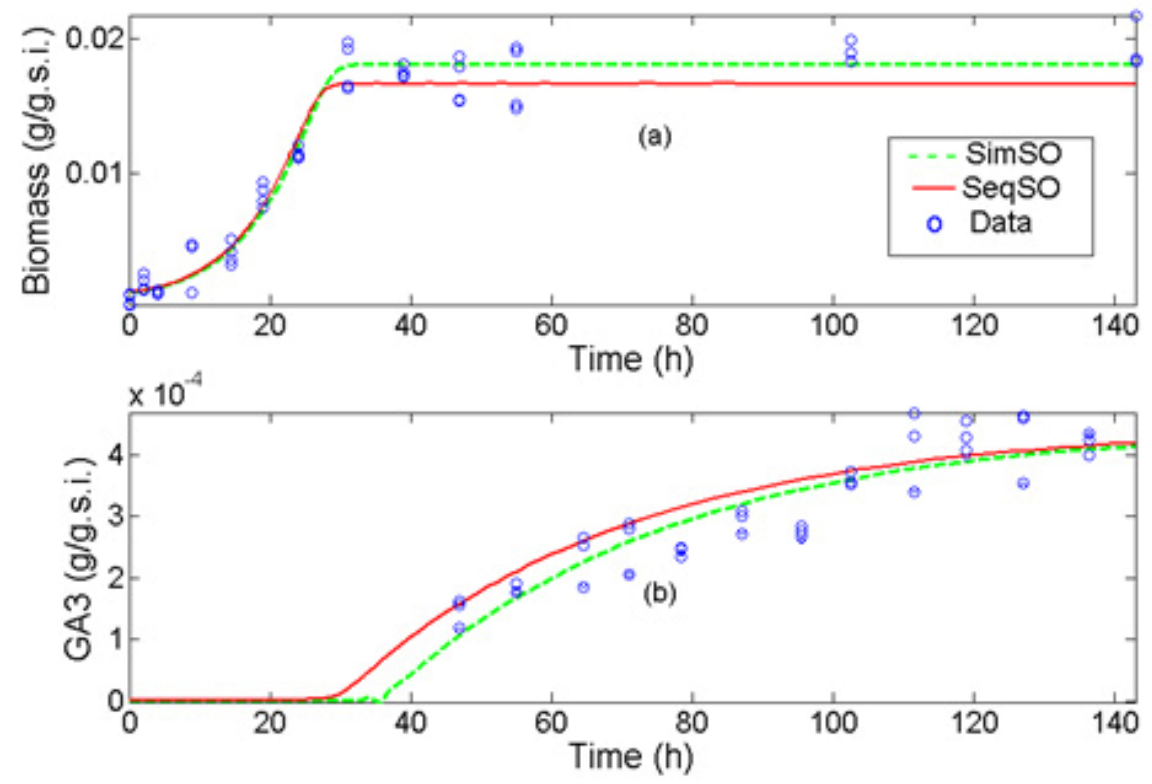

Figure 5. Model performance with optimal parameter estimates for cultivation condition $4\left(31^{\circ} \mathrm{C}\right.$ and 0.992). 